\title{
Comparing chemical and enzymatic synthesis of rich behenic lipids products: technological and nutritional potential
}

\author{
Julia Cristina ZUIN ${ }^{1}$ (D), Renata Luana de Pádua GANDRA ${ }^{1}$, Ana Paula Badan RIBEIRO², \\ Juliana Neves Rodrigues RACT ${ }^{3}$, Juliana Alves MACEDO ${ }^{1}$, Gabriela Alves MACEDO ${ }^{1 \star}$
}

\begin{abstract}
One of the current challenges of the food industry is to develop lipid bases with the desired technological performance for food application and with lower caloric value, in compliance with new legislations. In this context, the objective of this research is to compare chemical and enzymatic interesterification as methods for obtaining structured low-calorie lipids. Both processes are of commercial importance, since they can be used to modify the physical characteristics of fat without generating trans fatty acids. The lipid matrices used were olive oil, soybean oil and fully hydrogenated crambe oil, behenic acid source, presenting anti-obesogenic potential. Samples interesterified were characterized regarding the physicochemical behavior and regiospecific distribution in comparison to the simple mixture of the raw materials, in order to show the importance of the interesterification process. There was a reduction in their solid fat content after interesterification, which improved their physical properties and there was an increase in consistency, while the simple mixture did not represented a good option for industrial use. There was a $47 \%$ increase of saturated fatty acids at the $s n-1,3$ position after enzymatic synthesis. The results indicate that the structured lipids obtained can be a viable alternative to replace fats in foods low calorie.
\end{abstract}

Keywords: interesterification; low-calorie; fully hydrogenated crambe oil; obesity; regiospecificity; structured lipids.

Practical Application: Low-calorie structured lipids are partially absorbed and have technological functionality.

\section{Introduction}

Oils and fats play a fundamental role in the human diet, due to their physiological, metabolic and nutritive effects, in addition to providing essential fatty acids. However, excessive intake can cause harm to health, increasing the propensity to heart disease and obesity (Hammad \& Jones, 2017; Pinheiro-Castro et al., 2019). In this sense, combining the growing market demand, there is an enormous search for the development of technologies capable of modifying oils and fats, in the expectation of introducing a product with greater appeal of healthiness and that is suited to the applications of the food industry (Sivakanthan \& Madhujith, 2020).

Currently, structured lipids stand out with great potential, are synthesized to aggregate nutraceutical properties capable of meeting nutritional needs and providing interesting metabolic and physiological effects for the prevention and treatment of diseases in addition to the desired technological properties. Structured lipids can be defined as triacylglycerols modified by chemical or enzymatic catalysts, through the interesterification reaction, capable of altering the distribution of fatty acids in the glycerol molecule (Moreira et al., 2020; Wirkowska-Wojdyła et al., 2016).

The final molecular structure of triacylglycerol will influence its metabolic destination in the body, as well as its physicochemical properties, very important factors to control the functionality of the target products (Rohm et al., 2018). In this way, structured lipids offer the opportunity and convenience of modifying nutritional properties and bringing new applications in food, in regard to consumers, ingesting nutritionally healthier products, as well as for the food industry, adapting to new legislations.

Both methods of interesterification produce zero trans structured lipids and are capable of modifying the physical properties of oils, but the processes are different between them. The enzyme, a biocatalyst, has advantages compared to chemical interesterification, because of the high catalytic activity of the enzyme, the reaction occurs at lower temperatures, decreasing the thermal degradation of minor compounds. In addition, one of the main advantages of this method is the possibility of specificity of the enzyme, which can act at the $s n-1,3$ positions of triacylglycerol, allowing a more controlled distribution of fatty acids in the glycerol molecule. Another important factor refers to the possibility of reusing lipase numerous times, due to its immobilization, thus reducing the reaction costs. Regarding chemical interesterification, an alkaline catalyst is used and although it is relatively inexpensive, the possibility of reaching a specific composition in the final product is limited, due to the lack of specificity of the reaction, since the redistribution of fatty 
acids occurs randomly. In relation to the increase in scale and reaction costs, until then chemical interesterification has been used more frequently by the industry, however regarding the prospect of developing lipid products with specific compositions, aiming at nutraceutical application for example, enzymatic interesterification shows more attractiveness (Moreira et al., 2020; Rohm et al., 2018).

Structured lipids have been widely used by the oil and fat industries for the manufacture of margarines and shortenings due to the replacement of partially hydrogenated fats that contain trans fatty acids (Rohm et al., 2018). In order to manufacture a margarine analogue with low trans appeal, Li et al. (2018) used a mixture of soy oil and fully hydrogenated palm oil and demonstrated the feasibility of an enzymatic interesterification to obtain a product with healthier formulation potential and with appropriate physicochemical characteristics.

Fully hydrogenated crambe oil (Crambe abyssinica), is a white solid and due to the high presence of behenic acid, can be used as functional element of low-calorie fats (Arishima et al., 2009). Are low-cost industrial raw materials and are very useful for lipid technology (Akanda et al., 2020). Behenic acid is a saturated fatty acid consisting of 22 carbons (Şahan \& Paksoy, 2020; Xu et al., 2017) can be produced by complete hydrogenation of erucic acid (C22:1), since the latter is unsuitable for human consumption (Ribeiro et al., 2017; Stahl et al., 2018). Behenic acid has been used because it is partially absorbed by the human body, due to possible inhibition of the action of pancreatic lipase, with the potential to reduce calories in oils and fats (Moreira et al., 2017b; Silva et al., 2019).

Several studies have evaluated in vivo the effects of structured lipids formulated with behenic acid. Kanjilal et al. (2013) studied in rats and rabbits, Moreira et al. (2017b) in mice and animals from both studies did not develop obesity and exhibited reduced levels of total cholesterol, LDL cholesterol and triglycerides, being, therefore, a great ally in the fight against cardiovascular diseases and in the production of low-calorie lipids. In the study by Silva et al. (2019) in mice, the authors concluded that the structured lipid containing behenic acid has the ability to reduce postprandial inflammation and can promote the health and well-being of those who consume it.

In view of the advantages of enzymatic interesterification for potential application in lipid products, an important point to be evaluated is the maintenance of the physical-chemical characteristics by increasing the process and ensuring reproducibility, to preserve the quality of the final product and the use in industrial scale. Therefore, Moreira et al. (2020), analyzed a structured lipid composed of olive oil, soy oil and fully hydrogenated crambe oil with increased production and studied how the characteristics of the lipid responded to this increase. As a result, the researchers developed a controlled structured lipid synthesis process that demonstrated repeatability. Therefore, it was possible to increase the production of this lipid 50 times, making the process more suitable for industrial application.

In order to investigate dietary alternatives to help the population to avoid obesity, Silva et al. (2020) developed a structured lipid rich in behenic acid, resulting in a lipid capable of partially inhibiting pancreatic lipase in rats, which proved to be healthier than those that ate a conventional high-fat diet.

Thus, obtaining structured lipids can be an interesting alternative in the challenge of producing healthier foods, when associated with appropriate physical-chemical characteristics for application and industrial use.

Regarding the exposed, the objective of this study is to compare the products obtained by chemical (CI) or enzymatic interesterification (EI), using olive oil, soy oil and fully hydrogenated crambe oil (FHCO), as a source of behenic acid, due to its well-documented antiobesogenic potential and to evaluate the physical-chemical properties of the lipids produced to guarantee technological functionality for application in lipid-based foods, with excellent nutritional properties and lower caloric value.

\section{Materials and methods}

\subsection{Materials}

The soybean oil was purchased at the local supermarket (Campinas, Brazil), the fully hydrogenated crambe oil (FHCO) was donated by Chemyunion LTDA (São Paulo, Brazil) and the extra virgin olive oil was donated by Olivas do Sul (Cachoeira do Sul, Brazil). For the enzymatic interesterification reaction the immobilized Thermomyces lanuginosa lipase (Lipozyme TL IM, Novozymes ${ }^{\circledR}$ ) was used and for the chemical interesterification the sodium methoxide catalyst (Sigma Aldrich).

\subsection{Methods}

\section{Structured Lipid (SL) containing behenic acid production}

The structured lipids were produced from the interesterification (enzymatic or chemical) of a system prepared with olive oil, soybean oil and fully hydrogenated crambe oil (FHCO) in the ratio 43:43:14 (w/w), respectively.

Chemical Interesterification: The reaction took place in a glass-lined reactor, under vacuum and agitation at $500 \mathrm{rpm}$, at $100{ }^{\circ} \mathrm{C}$, for $20 \mathrm{~min}$, according to the optimization performed by Grimaldi et al. (2005). The catalyst used was the sodium methoxide. The reaction was concluded by adding distilled water and 5\% citric acid solution. The interesterified samples were carefully washed with distilled water $\left(80^{\circ} \mathrm{C}\right)$, to remove soaps and dried under vacuum, at $110^{\circ} \mathrm{C}$ for $30 \mathrm{~min}$ (Ribeiro, et al. 2009a).

Enzymatic Interesterification: The reaction was conducted based on the one described by Moreira et al. (2020), with some modifications. The reaction was carried out in a glass reactor with a capacity of $2 \mathrm{~L}\left(\right.$ Marconi $\left.^{\odot}\right)$, under vacuum and under stirring of $350 \mathrm{rpm}$ at a temperature of $60^{\circ} \mathrm{C}$. The reaction occurred for 4 hours with immobilized lipase at 10\% (w/w) (Lipozyme TL IM, Novozymes ${ }^{\circledR}$ ), previously conditioned.

\section{Physico-chemical characterization of simple mixtures and structured lipids obtained by the two processes}

Each system obtained by chemical or enzymatic interesterification went through the following characterization methodologies:

\section{Fatty acid composition}

The fatty acid composition analysis was performed using an Agilent 6850 Series GC System CGC gas chromatograph, after esterification performed according to Hartman \& Lago (1973). The fatty acid methyl esters were separated according to the AOCS Ce 1f-96 (2009) procedure in an Agilent DB-23 capillary column (50\% Cyanopropyl-methylpolysiloxane). The qualitative composition was determined by comparing peak retention times with those of the respective fatty acid standards. 
Partial acylglycerol content (HPSEC)

The analysis of classes of glyceride compounds were carried out according to Dobarganes et al. (2000). The analysis were performed with a Perkin Elmer LC-250 liquid chromatograph with a Sicon Analytic refractive index detector. The families of compounds were identified by comparing the elution times with standards of: triacylglycerols (TAG), diacylglycerols (DAG), monoacylglycerols (MAG) and free fatty acids (AG).

\section{Consistency}

Was determined using a microcomputer-controlled TA-XT Plus texture analyzer (Stable Micro Systems, Surrey, UK). Samples were heated in a microwave to approximately $70^{\circ} \mathrm{C}$ for complete melting of the crystals and placed in $50 \mathrm{~mL}$ beakers. Product conditioning was carried out in an incubator for $24 \mathrm{~h}$ at $5^{\circ} \mathrm{C}$ for fat crystallization and then for $24 \mathrm{~h}$ at $15^{\circ} \mathrm{C}$. An cone with a $60^{\circ}$ angle was used to determine the consistency of the samples. The test conditions were as follows: penetration distance $=10 \mathrm{~mm}$; velocity $=2 \mathrm{~mm} / \mathrm{s}$; time $=5 \mathrm{~s}$ (Stahl et al., 2018). The maximum compression force in (gf) was measured and the penetration data was converted into Yield Value, according to Haighton (1959). The samples were analyzed in quadruplicate and the results corresponded to the calculated means.

\section{Solid Fat Content and Melting Point}

It was determined using Bruker pc120 Minispec Nuclear Magnetic Resonance (NMR) Spectrometer (Bruker, Germany), together with dry baths with temperature range from $0^{\circ} \mathrm{C}$ to $70^{\circ} \mathrm{C}$, Tcon 2000 (Duratech, USA). The AOCS Cd 16b-93 Method was used: direct method with reading the samples in series at temperatures of $10 ; 15 ; 20 ; 25 ; 30 ; 35 ; 37.5 ; 40 ; 45 ; 50^{\circ} \mathrm{C}$, with tempering for unstabilized fats (American Oil Chemists Society, 2009). The determination was carried out in triplicate.

\section{Thermal behavior of crystallization}

The thermal analysis of the samples was performed with a Differential Scanning Calorimeters (DSC) model Q2000 (TA Instruments) according to the method AOCS Cj 1-94 (2009). The crystallization curve was obtained by heating at $80^{\circ} \mathrm{C}$ for $10 \mathrm{~min}$, with subsequent cooling from $80^{\circ} \mathrm{C}$ to $-80^{\circ} \mathrm{C}$ at a rate of $10^{\circ} \mathrm{C} / \mathrm{min}$. The data were processed with Universal V4.7A (TA Instruments, Waters LLC, New Castle).

\section{Regiospecific Distribution}

The regiospecific distribution of fatty acids in the triacylglycerol chain was determined by ${ }^{13} \mathrm{C}$ high resolution Nuclear Magnetic Resonance. $250 \mathrm{mg}$ samples were dissolved in $0.5 \mathrm{~mL}$ of deuterated chloroform in $5 \mathrm{~mm}$ NMR tubes, and the spectra were recorded on a Bruker Advance DPX spectrometer operating at $300 \mathrm{MHz}$. The determination was performed at the frequency of $75.8 \mathrm{MHz}$ with a $5 \mathrm{~mm}$ multi-nuclear probe operating at $30^{\circ} \mathrm{C}$, according to the method described by Vlahov (2005).

\subsection{Statistical analysis}

The statistical analysis were based on the Analysis of Variance (ANOVA) and Tukey's Test, to determine the significant differences of the averages at the level of probability of $5 \%(\mathrm{p}<0.05)$, using the software Statistica 8.0.

\section{Results and discussion}

\subsection{Fatty acid composition and distribution in triacylglycerols}

Figure 1 shows the fatty acid classes of the mixture composed of soy oil, olive oil and fully hydrogenated crambe oil, before and after chemical and enzymatic interesterification. It was possible to observe that there was no variation in the composition in fatty acids after performing the interesterification process, corroborating with data from the literature, which affirm that the redistribution of fatty acids occurs in the molecules of triacylglycerols and the fatty acids remain unchanged (Wirkowska-Wojdyła et al., 2016).

The main fatty acids present in the interesterified lipids were C18:1 (36\%), C18:2 (27\%) and C16:0 (13\%), determined by the total fatty acid composition of the initial raw materials, thus, result in products that have the same initial fatty acid composition, but in different positions in the triacylglycerol molecule, influencing the consistency and plasticity of the fat. A structured lipid with $6.5 \%$ behenic acid was obtained, an important data for determining antiobesogenic capacity in vivo. Similar concentration of behenic acid to that found in structured lipids in the literature obtained positive results when added to the diet of mice (Moreira et al., 2017b; Silva et al., 2019). Thus justifying that the amount of behenic acid found in this study is adequate to promote health benefits.

It was found that after the reaction time, new compounds were formed through the reorganization of fatty acids in the glycerol molecule, mainly with behenic and stearic acids. In particular, a decrease in trisaturated triacylglycerols and the formation of new classes of TAGs is observed, with the distribution of behenic and stearic saturated acids. Fact that leads to the changes that were observed and will be discussed below, in the physicalchemical characteristics after the processes of interesterification in comparison to the simple mixture, such as, for example, the melting point, solids content and change of consistency at room temperature, being able to be observed with bare eye, which differed considerably from its raw materials.

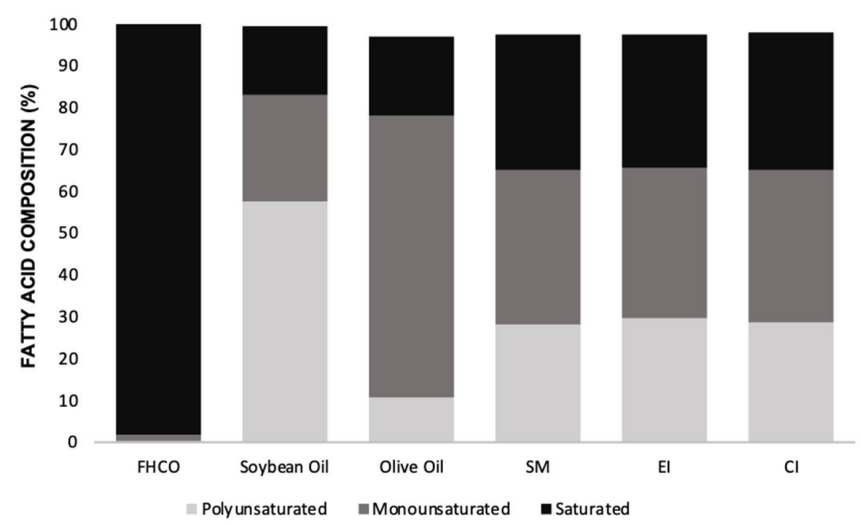

Figure 1. Composition in fatty acid classes (w/w \%) of fully hydrogenated crambe oil (FHCO), soybean oil, olive oil, simple mixture (SM) and samples after enzymatic (EI) and chemical interesterification (CI). 
Through the HPSEC analysis it was possible to determine the proportion of triacylglycerols (TAG), diacylglycerols (DAG) and monoacylglycerols (MAG) + free fatty acids (AG), in each of the samples, as shown in Figure 2. The simple mixture, showed $100 \%$ TAG and it is observed that the proportion of TAG was higher in all samples, proving that there was the hydrolysis process followed by esterification in the two interesterification processes, resulting in a small amount of $M G+A G$ at the end of the reaction, as desired. Similar fact to that found in the study by Guedes et al., (2014), in which the authors evaluated chemical interesterification using mixtures of soy oil and fully hydrogenated crambe oil. The low concentration of free MG + AG guarantees the efficiency in the interesterification process (Rohm et al., 2018).

\subsection{Consistency}

Consistency is a very important characteristic for the quality of products with lipid bases. The concept of consistency is analyzed by two criteria: hardness and spreadability (Oliveira et al., 2015). Figure 3 represents the texture obtained from the structured lipids and the simple mixture.

The literature indicates the method described by Haighton (1959) for assessing the consistency of lipids, which uses the parameter yield value (YV), classifying the fats according to their hardness and spreadability. The results were evaluated according to the yield value obtained. Haighton (1959) still indicates the application range of some products using the $\mathrm{YV}\left(\mathrm{gf} / \mathrm{cm}^{2}\right)$. For example: margarine has a YV of $200-1000 \mathrm{gf} / \mathrm{cm}^{2}$, puff pastry fats in the range of $800-1600 \mathrm{gf} / \mathrm{cm}^{2}$, soft shortenings of $50-300 \mathrm{gf} / \mathrm{cm}^{2}$ and conventional bakery shortenings $200-700 \mathrm{gf} / \mathrm{cm}^{2}$. While hard fats from bakery and confectionery products are in the range of $300-900 \mathrm{gf} / \mathrm{cm}^{2}$ and $150-600 \mathrm{gf} / \mathrm{cm}^{2}$, respectively.

However, it must be emphasized that the temperature must be taken into account. Due to the analysis being carried out at $15{ }^{\circ} \mathrm{C}$, this factor indicates that the samples with higher YV contribute to a greater consistency of the product at a temperature below room temperature, indicating that they have attributes necessary especially for use in refrigerated products.

Taking into account the yield value, the analyzed samples have potential for application in different food products, such as margarines, confectionery and bakery products in the case of samples prepared with enzymatic interesterification and puff pastry fat specifically for the fat produced through the chemical interesterification.

According to Chiu et al. (2007), the texture in margarines is a fundamental parameter, since these products need to have good spreadability properties under refrigeration and not release oil when exposed to room temperature.

The sample produced by chemical interesterification falls into the very hard category, but with a spreadability limit, since it has YV between 1000 and $1500 \mathrm{gf} / \mathrm{cm}^{2}$. Regarding the enzymatically synthesized sample, it is in the best category available, being classified as plastic and spreadable. In the sample composed only by the simple mixing the raw materials, despite visually appearing harder at room temperature, when the probe

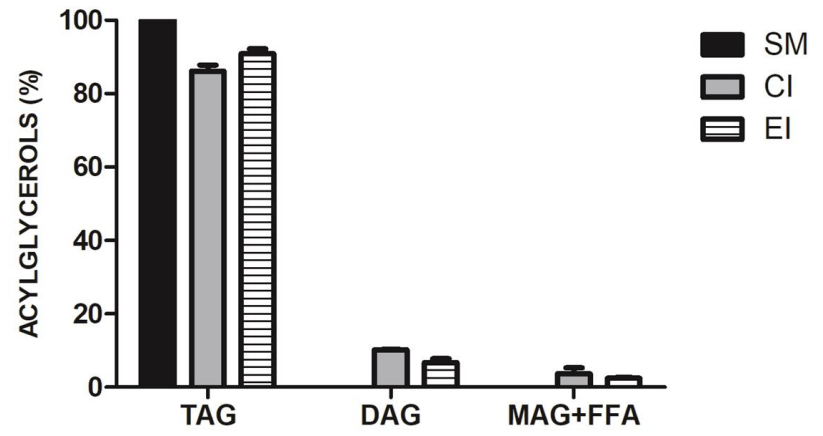

Figure 2. Acylglycerol composition of samples (\%) in simple mixture (SM) and after enzymatic (EI) and chemical interesterification (CI). TAG: Triacylglycerols; DAG: Diacylglycerols; MAG + FFA: Monoacylglycerols + free fat acids.

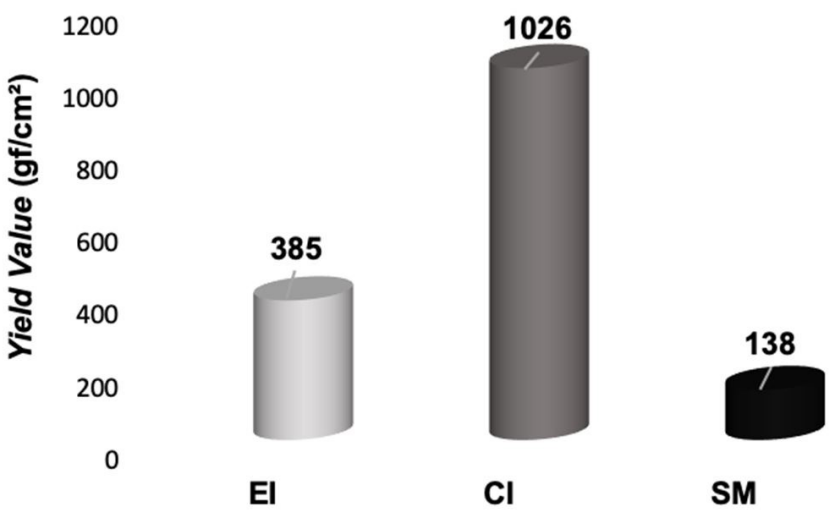

Figure 3. Texture of chemically (CI) and enzymatically (EI) interesterified structured lipids and simple mixture (SM) expressed as Yield Value $\left(\mathrm{gf} / \mathrm{cm}^{2}\right)$.

penetrated carrying out the analysis, the sample did not offer resistance and therefore presented a very low yield value, this indicates that there was no satisfactory structure, emphasizing that it would not be a good option for industrial use, as it does not have the necessary plasticity. This fact confirms that the simple mixing of fats is not an option for industrial use as reported by Kellens \& Calliauw (2014).

\subsection{Solids profile}

The solid profile is fundamental for the characterization of lipid base for application, since the solid fat content (SFC) is a parameter that influences physical properties, such as spreadability, mass aeration, consistency and stability, also influencing sensory properties (Samuel et al., 2018). Figure 4 shows the solid curves of the control mixture and of the interesterified samples. The solid fat content of the simple mixture was much higher than that of the structured lipid samples, consequently, a higher temperature was necessary for the complete fusion of this sample to occur, as expected. Some studies have also reported 
that after the interesterification process there was a reduction in the content of solid fat, due to the decrease in trisaturated TAGs and the expansion of monounsaturated TAGs (Ribeiro et al., 2017; Zhao et al., 2014).

At $10^{\circ} \mathrm{C}$, the samples showed $\mathrm{SFC}$ values between $18 \%$ and $20 \%$, which decreased until complete melting between $42{ }^{\circ} \mathrm{C}$, for the structured lipids and $60^{\circ} \mathrm{C}$ for the simple mixture, this significant difference between the values of the simple mixture and the interesterified samples occurred due to the formation of new triacylglycerols with different melting points.

SFC at low temperatures $\left(4^{\circ} \mathrm{C}\right.$ to $\left.10{ }^{\circ} \mathrm{C}\right)$ determines the spreadability of fat in refrigeration temperatures and should not exceed $32 \%$ at $10^{\circ} \mathrm{C}$ (Wassell \& Young, 2007). Therefore, for this criterion, all samples analyzed met the requirement and offer the desired spreadability for use in refrigerated products. The SFC has significant involvement on the performance of margarine melting and spreads in various temperature ranges, an especially relevant factor when it comes to products with low fat contents, as is the case of the analyzed samples (Wassell \& Young, 2007).

Fats reach their melting point when the SFC is close to 4 to $5 \%$ (Karabulut et al., 2004). Therefore, samples of structured lipids, both EI and CI, demonstrated adequate values for a product with desirable melting in the mouth, differing from the simple mixture sample, which, on the contrary, presented $13 \%$ solids at body temperature, which represents a product with undesirable waxy sensation in the mouth and once again emphasizing the non-quality for use of the simple mixture.

The application of new fats produced in processed foods is based on the comparison of their physical properties to the characteristics of commercial fats for specific use, at different temperatures. Specifically in the case of the solid profile, it has a considerable correlation to the characteristics of margarines and vegetable fats, considering that it is used as the main instrument to specify and select fats in food applications (Ribeiro, et al., 2009b; Lee et al., 2008; Wassell \& Young, 2007).

The comparison of structured lipids of same chemical composition obtained by chemical and enzymatic process is essential, considering that the processes have very different costs and can produce lipids in a very specific and differentiated way, both from technological and nutritional point of view, depending on the enzyme employed. To date, no published results are known

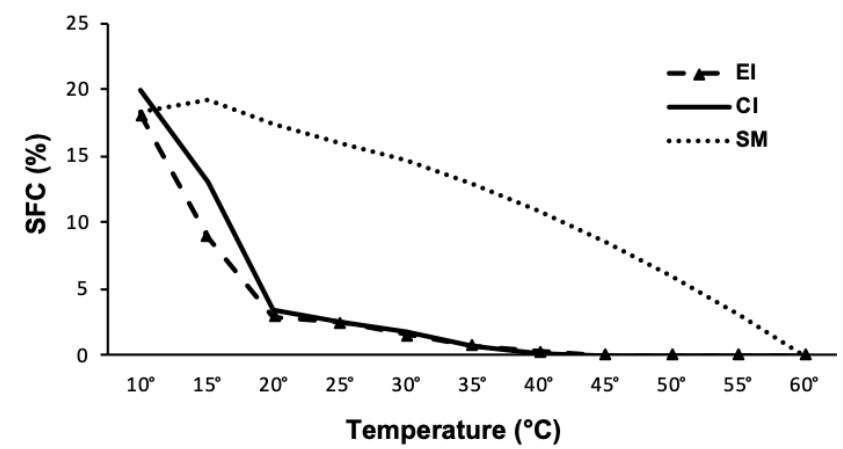

Figure 4. Solids profile of chemically (CI) and enzymatically (EI) interesterified and simple mixture (MS) samples as a function of temperature. to compare the two processes in order to justify the process in terms of its desired application and the possible nutritional benefit provided by fat.

\subsection{Thermal behavior - crystallization profile by DSC}

Through the analysis of the crystallization thermograms obtained by DSC (Figure 5) it is possible to observe the crystallization characteristics of the SM, EI and CI. The fully hydrogenated crambe oil starts its crystallization at around $65^{\circ} \mathrm{C}$, showing only one peak. It is known that trisaturated triacylglycerols because they have higher melting point, crystallize first. Therefore, due to the fact that OCTH is composed of only saturated fatty acids, it has this characteristic.

Checking the crystallization profile by DSC, it is noted that the sample obtained by chemical interesterification showed more trisaturated when compared to the enzymatically synthesized sample.

After interesterification, a great change in the crystallization profile is observed, since the tri and unsaturated triacylglycerols were redistributed to monounsaturated and tri unsaturated, and because they correspond to low melting point TAGs, they are responsible for the third peak of crystallization.

As in the study by Moreira et al. (2020), the simple mixture exhibited a wide range of crystallization, ranging from 41.2 to $-61.6{ }^{\circ} \mathrm{C}$, combined with a high enthalpy $(39.9 \mathrm{~J} / \mathrm{g})$. After the chemical and enzymatic interesterification reactions, the formation of a single peak is noted, showing a narrower range of crystallization temperature, in this case, from approximately 19.0 to $-49.0^{\circ} \mathrm{C}$, for the two interesterifications, with an enthalpy similar to the first peak of the simple mixture. These changes may have occurred due to the new distribution of fatty acids in the triacylglycerol molecule after the interesterification process (Shin et al., 2009).

\subsection{Regiospecific distribution}

Regiospecific analysis is essential in interesterified samples as it enables the observation of the distribution of saturated, monounsaturated and polyunsaturated fatty acids in glycerol, a very important factor to determine the physical properties of fats and to observe how lipids will be absorbed and interfere with the metabolism (Berry, 2009; Ract et al., 2015; Ribeiro et al.,

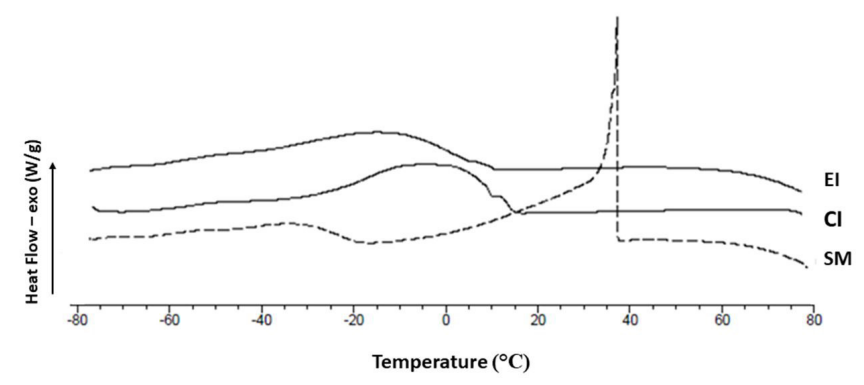

Figure 5. Crystallization thermograms of simple mixture (SM); enzymatic interesterification (EI) and chemical interesterification (CI). 
2017). In addition, the position of each fatty acid in the glycerol structure significantly affects the bioavailability of this fatty acid in the body, so using lipases in enzymatic interesterification, that allows the insertion of fatty acids in positions of interest in the glycerol, becomes a very large and desired advantage, aiming to meet the interests of the industry and also nutritionally in relation to the health of consumers (Sivakanthan \& Madhujith, 2020). Another advantage of lipid structuring is the insertion of essential fatty acids to the lipid, contributing to public health (Kadhum \& Shamma, 2017; Mensink et al., 2016).

Figure 6 shows the distribution of saturated, monounsaturated and polyunsaturated fatty acids in mass percentage, found at the $s n-2$ and $s n-1,3$ positions of glycerol, for the samples of simple mixture, enzymatic interesterification and chemical interesterification. The different letters for each sample when comparing $s n-1,3$ and $s n-2$ indicate a significant difference. This significant difference in the distribution profile between the samples confirms the rearrangement of fatty acids between the glycerol positions.

In general, there was a prevalence of saturated fatty acids at the $s n-1,3$ position, as is typical for natural vegetable oils, keeping unsaturated fatty acids in the central position of glycerol (Berry, 2009; Karupaiah \& Sundram, 2007; Ribeiro et al., 2017). This aspect is important because when making the synthesis it is not desired that the lipids do not follow their natural distribution, otherwise it can cause problems in the absorption and digestion (Sivakanthan \& Madhujith, 2020). In this context, maintaining $s n-2$ position preserved means that a more natural fat was obtained, but now with more suitable physical-chemical properties for application (Wirkowska-Wojdyła et al., 2016).

As expected, after the chemical interesterification, the distribution of fatty acids in the three positions of the TAG was more balanced, due to the characteristic randomization of the chemical reaction. Fact similar to that was found with

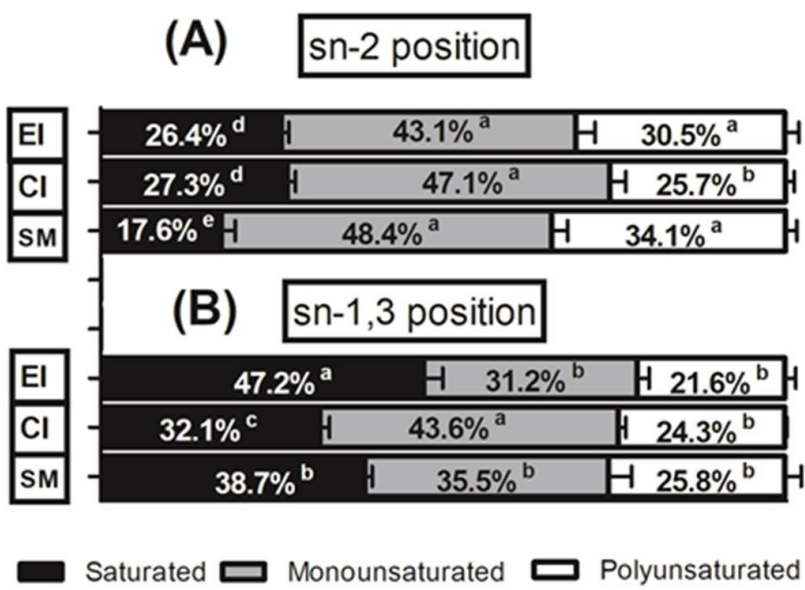

Figure 6. Fatty acid distribution (w/w \%) at the $s n-2$ and $s n-1,3$ positions of triacylglycerols in enzymatic (EI) and chemically (CI) interesterified structured lipids and in simple mixture (SM). Same letters in same columns indicate that there is no significant difference between the averages analyzed in Tukey test $(\mathrm{p} \leq 0.05)$. structured lipids in the study by Guedes et al., (2014). On the other hand, after the enzymatic interesterification there was a predominance of saturated at the $s n-1,3$ positions and maintenance of monounsaturated at the $s n-2$ position, demonstrating an enzymatic specificity, an important characteristic to design special lipids for nutrition (Sivakanthan \& Madhujith, 2020).

With regard specifically to the structured lipid produced by enzymatic interesterification, for the $s n-2$ position of mono and polyunsaturated, the result was significantly similar to the simple mixture, that is, the enzyme did not act at the $s n-2$ position. However, with respect to saturated fatty acids, a variation was noticed. A similar result was observed in the study by Pacheco et al. (2015), where the researchers investigated the possibility of keeping the $s n-2$ fatty acid composition unchanged, using different reaction conditions, however, the results indicated that although they also used specific $s n-1,3$ lipase, the initial fatty acid composition of the $s n-2$ position of the TAG changed. Regardless of this, the results showed that compared to non-specific or chemical catalysts, the use of these studied biocatalysts remains as preferred, as it maintains the original profile on a larger scale.

In the study by Ract et al. (2015) there were no saturated fatty acids at the $s n-2$ position when evaluated in the simple mixture. However, unexpectedly, after the use of specific $s n-1,3$ enzyme, approximately $8 \%$ of saturated fatty acids were incorporated at the $s n-2$ position, possibly due to the occurrence of acyl migration. The authors pointed out that acyl migration cannot be completely avoided and the complete prevention of the phenomenon is very difficult. Lopes et al. (2016) emphasized that the increase in the reaction time is not favorable for both the yield and the selectivity of the interesterification reaction and the prolonged reaction time can cause increased acyl migration.

After the enzyme catalyzed reaction, there was a statistically significant increase in saturated fatty acids at the $s n-1,3$ position (ranging from $38.7 \%$ in the simple mixture to $47.2 \%$ in the EI). In other words, there was an increase of $22 \%$ after the redistribution of fatty acids. In enzymatic interesterification, a $47 \%$ higher result of saturated fatty acids found at the $s n-1,3$ position was obtained in relation to chemical interesterification. In addition, the enzymatically obtained structured lipid showed more unsaturated fatty acids at the $s n-2$ position of the TAG, with $73.6 \%$ of the total unsaturated in that position.

In comparison to $\mathrm{CI}$, the sample produced by enzymatic interesterification was shown to be superior from a nutritional point of view. Very beneficial and desirable result, fulfilling one of the objectives of the present study, considering that the absorption of fats occurs mainly at the $s n-2$, as it is interesting to keep unsaturated at this position (Wang et al. 2012). It is reported in the literature that human metabolism is able to absorb polyunsaturated fatty acids at the $s n-2$ position more easily (Sivakanthan \& Madhujith, 2020). Therefore, there is another advantage of the enzyme-produced lipid, which presented $18.6 \%$ more polyunsaturated fatty acids at the $s n-2$ position than the lipid after the chemical reaction.

The evaluation of the distribution of fatty acids in glycerol is extremely important, considering the possibility of causing negative impact on health, depending on the location of the fatty 
acid in the molecule. According to a study by Miyamoto et al. (2018), an interesterified diet in rats led to weight gain, glucose intolerance, increased cellular stress markers and impaired hepatic metabolic parameters, possibly due to a higher saturated fatty acid content at the $s n-2$ position than the control group.

Although the simple mixing of the raw materials showed higher value of unsaturated at the $s n-2$ position in comparison to the interesterified samples, the other analysis, such as solids profile and consistency, suggest that the SM is not as efficient for application due to its low plasticity. Therefore, it can be said that the interesterification process modified the positions of fatty acids in the glycerol structure, which caused the changes reported in the physical and chemical characteristics of the interesterified samples, making the samples more suitable for application in food (Moreira et al. 2017a).

It can be highlighted that, specifically regarding the content of saturated fatty acids at the $s n-1,3$ and $s n-2$ positions, the lipase used to catalyze the reaction under the conditions described acted with low specificity and added saturated fatty acids in all positions of TAG, that is, behenic acid was incorporated in the three positions of TAG, as well as in the study by Moreira et al. (2017a) and Ract et al. (2015). An advantage of incorporating some amount of behenic acid at the $s n-2$ position is due to its ability to have its absorption reduced. In other words, some authors suggest that partial inhibition of pancreatic lipase can happen through the ingestion of structured lipids composed of long-chain fatty acids, such as behenic acid, making it completely non-absorbable (Arishima et al., 2009; Kanjilal et al., 2013).

\section{Conclusion}

Both chemical and enzymatic interesterification processes promoted changes in the physical-chemical characteristics of lipids when compared to the simple mixing of raw materials. However, enzymatic synthesis demonstrated a specificity advantage for the incorporation of fatty acids in positions of interest in TAGs, crucial for obtaining unique properties. From the perspective of developing special lipid products with specific compositions, aiming at nutraceutical applications, for example, the enzymatic reaction proved to be more attractive compared to chemically catalyzed. In contrast, CI stands out for promoting higher consistency and can be applied for the development of different products. Considering that a large part of the population frequently consumes industrialized products, it is very important to develop special lipids with good performance for nutritional application, such as these low-calorie structured lipids rich in behenic acid that are partially absorbed in the body and which have functionality and application capacity in different lipidbased foods.

\section{Acknowledgements}

The authors acknowledge the financial support received from the Coordination of Superior Level Staff Improvement (CAPES), Finance Code 001, process number: 88882.435037/2019-01 and National Council for Scientific and Technological Development (CNPq), process number: 305224/2020-4.

\section{References}

Akanda, J. H., Norazlina, M. R., Azzatul, F. S., Mamat, H., Lee, J. S., Norliza, J., Mansoor, A. H., Khan, F., Matanjun, P., \& Sarker, Z. I. (2020). Hard fats improve the physicochemical and thermal properties of seed fats for applications in confectionery products hard fats improve the physicochemical and thermal. Food Reviews International, 36(6), 601-625. http://dx.doi.org/10.1080/87559129 .2019 .1657443 .

American Oil Chemists Society - AOCS. (2009). Official methods and recommended practices of the American Oil Chemists' Society (6th ed.). Chicago: AOCS.

Arishima, T., Tachibana, N., Kojima, M., Takamatsu, K., \& Imaizumi, K. (2009). Screening of resistant triacylglycerols to the pancreatic lipase and their potentialities as a digestive retardant. Journal of Food Lipids, 16(1), 72-88. http://dx.doi.org/10.1111/j.1745-4522.2009.01133.x.

Berry, S. E. E. (2009). Triacylglycerol structure and interesterification of palmitic and stearic acid-rich fats: an overview and implications for cardiovascular disease. Nutrition Research Reviews, 22(1), 3-17. http://dx.doi.org/10.1017/S0954422409369267. PMid:19442321.

Chiu, M. C., Grimaldi, R., \& Gioielli, L. A. (2007). Fracionamento a seco da gordura de frango em escala piloto. Revista Brasileira de Ciências Farmacêuticas, 43(3), 421-434. http://dx.doi.org/10.1590/ S1516-93322007000300011.

Dobarganes, M. C., Velasco, J., \& Dieffenbacher, A. (2000). Determination of polar compounds, polymerized and oxidized triacylglycerols, and diacylglycerols in oils and fats. Pure and Applied Chemistry, 72(8), 1563-1575.

Grimaldi, R., Gonçalves, L. A. G., \& Ando, M. Y. (2005). Otimização da reação de interesterificação química de óleo de palma. Quimica Nova, 28(4), 633-636. http://dx.doi.org/10.1590/S0100-40422005000400015.

Guedes, A. M. M., Ming, C. C., Ribeiro, A. P. B., Da Silva, R. C., Gioielli, L. A., \& Gonçalves, L. A. G. (2014). Physicochemical properties of interesterified blends of fully hydrogenated crambe abyssinica oil and soybean oil. JAOCS. Journal of the American Oil Chemists Society, 91(1), 111-123. http://dx.doi.org/10.1007/s11746-013-2360-7.

Haighton, A. J. (1959). The measurement of the hardness of margarine and fats with cone penetrometers. Journal of the American Oil Chemists' Society, 36(8), 345-348. http://dx.doi.org/10.1007/BF02640051.

Hammad, S. S., \& Jones, P. J. (2017). Dietary fatty acid composition modulates obesity and interacts with obesity-related genes. Lipids, 52(10), 803-822. http://dx.doi.org/10.1007/s11745-017-4291-9. PMid:28889206.

Hartman, L., \& Lago, R. C. (1973). Rapid preparation of fatty acid methyl esters from lipids. Laboratory Practice, 22(6), 475-476. PMid:4727126.

Kadhum, A. A. H., \& Shamma, M. N. (2017). Edible lipids modification processes: a review. Critical Reviews in Food Science and Nutrition, 57(1), 48-58. http://dx.doi.org/10.1080/10408398.2013.848834. PMid:26048727.

Kanjilal, S., Kaki, S. S., Rao, B. V. S. K., Sugasini, D., Rao, Y. P., Prasad, R. B. N., \& Lokesh, B. R. (2013). Hypocholesterolemic effects of low calorie structured lipids on rats and rabbits fed on normal and atherogenic diet. Food Chemistry, 136(1), 259-265. http://dx.doi. org/10.1016/j.foodchem.2012.07.116. PMid:23017421.

Karabulut, I., Turan, S., \& Ergin, G. (2004). Effects of chemical interesterification on solid fat content and slip melting point of fat/oil blends. European Journal of Lipid Science and Technology, 218, 224-229.

Karupaiah, T., \& Sundram, K. (2007). Effects of stereospecific positioning of fatty acids in triacylglycerol structures in native and randomized 
fats: a review of their nutritional implications. Nutrition \& Metabolism, 4(1), 16. http://dx.doi.org/10.1186/1743-7075-4-16. PMid:17625019.

Kellens, M., \& Calliauw, G. (2014). Oil modification processes. Fats in Food Technology, 2e, 133-167. https://doi.org/10.1002/9781118788745.ch4.

Lee, J. H., Akoh, C. C., \& Lee, K.-T. (2008). Physical properties of trans-free bakery shortening produced by lipase-catalyzed interesterification. Journal of the American Oil Chemists' Society, 85(1), 1-11. http:// dx.doi.org/10.1007/s11746-007-1155-0.

Li, Y., Zhao, J., Xie, X., Zhang, Z., Zhang, N., \& Wang, Y. (2018). A low trans margarine fat analog to beef tallow for healthier formulations: optimization of enzymatic interesterification using soybean oil and fully hydrogenated palm oil. Food Chemistry, 255, 405-413. http:// dx.doi.org/10.1016/j.foodchem.2018.02.086. PMid:29571493.

Lopes, T. I. B., Ribeiro, M. D. M. M., Ming, C. C., Grimaldi, R., Gonçalves, L. A. G., \& Marsaioli, A. J. (2016). Comparison of the regiospecific distribution from triacylglycerols after chemical and enzymatic interesterification of high oleic sunflower oil and fully hydrogenated high oleic sunflower oil blend by carbon-13 nuclear magnetic resonance. Food Chemistry, 212, 641-647. http://dx.doi. org/10.1016/j.foodchem.2016.06.024. PMid:27374579.

Mensink, R. P., Sanders, T. A., Baer, D. J., Hayes, K. C., Howles, P. N., \& Marangoni, A. (2016). The increasing use of interesterified lipids in the food supply and their effects on health parameters. Advances in Nutrition, 7(4), 719-729. http://dx.doi.org/10.3945/an.115.009662. PMid:27422506.

Miyamoto, J. É., Ferraz, A. C. G., Portovedo, M., Reginato, A., Stahl, M. A., Ignacio-Souza, L. M., Chan, K. L., Torsoni, A. S., Torsoni, M. A., Ribeiro, A. P. B., \& Milanski, M. (2018). Interesterified soybean oil promotes weight gain, impaired glucose tolerance and increased liver cellular stress markers. The Journal of Nutritional Biochemistry, 59, 153-159. http://dx.doi.org/10.1016/j.jnutbio.2018.05.014. PMid:30005920.

Moreira, D. K. T., Gandra, R. L. de P., Zuin, J. C., Ract, J. N. R., Ribeiro, A. P. B., Macedo, J. A., Gambero, A., Akil, E., Torres, A. G., \& Macedo, G. A. (2020). Synthesis and characterization of structured lipid rich in behenic acid by enzymatic interesterification. Food and Bioproducts Processing, 122, 303-310. http://dx.doi.org/10.1016/j. fbp.2020.06.005.

Moreira, D. K. T., Ract, J. N. R., Ribeiro, A. P. B., \& Macedo, G. A. (2017a). Production and characterization of structured lipids with antiobesity potential and as a source of essential fatty acids. Food Research International, 99(1), 713-719. http://dx.doi.org/10.1016/j. foodres.2017.06.034. PMid:28784535.

Moreira, D. K. T., Santos, P. S., Gambero, A., \& Macedo, G. A. (2017b). Evaluation of structured lipids with behenic acid in the prevention of obesity. Food Research International, 95, 52-58. http://dx.doi. org/10.1016/j.foodres.2017.03.005. PMid:28395825.

Oliveira, G. M., Stahl, M. A., Ribeiro, A. P. B., Grimaldi, R., Cardoso, L. P., \& Kieckbusch, T. G. (2015). Development of zero trans/low sat fat systems structured with sorbitan monostearate and fully hydrogenated canola oil. European Journal of Lipid Science and Technology, 117(11), 1762-1771. http://dx.doi.org/10.1002/ejlt.201400559.

Pacheco, C., Crapiste, G. H., \& Carrín, M. E. (2015). Study of acyl migration during enzymatic interesterification of liquid and fully hydrogenated soybean oil. Journal of Molecular Catalysis. B, Enzymatic, 122, 117-124. http://dx.doi.org/10.1016/j.molcatb.2015.08.023.

Pinheiro-Castro, N., Silva, L. B. A. R., Novaes, G. M., \& Ong, T. P. (2019). Hypercaloric diet-induced obesity and obesity-related metabolic disorders in experimental models. In P. C. Guest (Org.), Reviews on biomarker studies of metabolic and metabolism-related disorders.
Advances in Experimental Medicine and Biology (pp. 149-161). Cham: Springer. http://dx.doi.org/10.1007/978-3-030-12668-1_8

Ract, J. N. R., Soares, F. A. S. D. M., Rodrigues, H. G., Bortolon, J. R., Murata, G. M., Gonçalves, M. I. A., Hatanaka, E., Curi, R., \& Gioielli, L. A. (2015). Production of vegetable oil blends and structured lipids and their effect on wound healing. Brazilian Journal of Pharmaceutical Sciences, 51(2), 415-427. http://dx.doi.org/10.1590/ S1984-82502015000200019.

Ribeiro, A. P. B., Basso, R. C., Grimaldi, R., Gioielli, L. A., Santos, A. O., Cardoso, L. P., \& Gonçalves, L. A. G. (2009a). Influence of chemical interesterification on thermal behavior, microstructure, polymorphism and crystallization properties of canola oil and fully hydrogenated cottonseed oil blends. Food Research International, 42(8), 1153-1162. http://dx.doi.org/10.1016/j.foodres.2009.05.016.

Ribeiro, A. P. B., Grimaldi, R., Gioielli, L. A., \& Gonçalves, L. A. (2009b). Zero trans fats from soybean oil and fully hydrogenated soybean oil: physico-chemical properties and food applications. Food Research International, 42(3), 401-410. http://dx.doi.org/10.1016/j. foodres.2009.01.012.

Ribeiro, M. D. M. M., Ming, C. C., Lopes, T. I. B., Grimaldi, R., Marsaioli, A. J., \& Gonçalves, L. A. G. (2017). Synthesis of structured lipids containing behenic acid from fully hydrogenated Crambe abyssinica oil by enzymatic interesterification. Journal of Food Science and Technology, 54(5), 1146-1157. http://dx.doi.org/10.1007/s13197017-2540-9. PMid:28416864.

Rohm, H., Schäper, C., \& Zahn, S. (2018). Interesterified fats in chocolate and bakery products: a concise review. Lebensmittel-Wissenschaft + Technologie, 87, 379-384. http://dx.doi.org/10.1016/j.lwt.2017.08.076.

Şahan, N., \& Paksoy, H. (2020). Designing behenic acid microcapsules as novel phase change material for thermal energy storage applications at medium temperature. International Journal of Energy Research, 44(5), 3922-3933. http://dx.doi.org/10.1002/er.5193.

Samuel, C. B., Joy, E.-E., \& Barine, K.-K. D. (2018). Effect of chemical interesterification on the physicochemical characteristics and fatty acid profile of bakery shortening produced from shea butter and fluted pumpkin seed oil blend. American Journal of Food Science and Technology, 6(4), 187-194. http://dx.doi.org/10.12691/ajfst-6-4-8.

Shin, J.-A., Akoh, C. C., \& Lee, K.-T. (2009). Production and physicochemical properties of functional-butterfat through enzymatic interesterification in a continuous reactor. Journal of Agricultural and Food Chemistry, 57(3), 888-900. http://dx.doi.org/10.1021/ jf802678a. PMid:19138078.

Silva, R. M., Moreira, D. K. T., Zarricueta, M. L., Caria, C. R. P., Macedo, J. A., Macedo, G. A., \& Gambero, A. (2019). The postprandial inflammatory response is attenuated by a dietary structured lipid containing behenic acid. Journal of Functional Foods, 58, 350-354. http://dx.doi.org/10.1016/j.jff.2019.05.013.

Silva, R. M., Zarricueta, M. L., Moreira, D. K. T., Morais, T. R., Rizzardi, K. F., Parisotto, T. M., Gandra, R. L. de P., Zuin, J. C., Caria, C. R. P., Macedo, J. A., Macedo, G. A., \& Gambero, A. (2020). Structured lipid containing behenic acid versus orlistat for weight loss: an experimental study in mice. PharmaNutrition, 14, 100213. http:// dx.doi.org/10.1016/j.phanu.2020.100213.

Sivakanthan, S., \& Madhujith, T. (2020). Current trends in applications of enzymatic interesterification of fats and oils : a review. LebensmittelWissenschaft + Technologie, 132, 109880. http://dx.doi.org/10.1016/j. lwt.2020.109880.

Stahl, M. A., Buscato, M. H. M., Grimaldi, R., Cardoso, L. P., \& Ribeiro, A. P. B. (2018). Structuration of lipid bases with fully hydrogenated crambe oil and sorbitan monostearate for obtaining zero-trans/ 
low sat fats. Food Research International, 107, 61-72. http://dx.doi. org/10.1016/j.foodres.2018.02.012. PMid:29580526.

Vlahov, G. (2005). 13C nuclear magnetic resonance spectroscopy to check 1,3-random, 2-random pattern of fatty acid distribution in olive oil triacylglycerols. Spectroscopy, 19(2), 109-117. http://dx.doi. org/10.1155/2005/765236.

Wang, Y., Xia, L., Xu, X., Xie, L., \& Duan, Z. (2012). Lipase-catalyzed acidolysis of canola oil with caprylic acid to produce medium-, longand medium-chain-type structured lipids. Food and Bioproducts Processing, 90(4), 707-712. http://dx.doi.org/10.1016/j.fbp.2012.02.003.

Wassell, P., \& Young, N. W. G. (2007). Food applications of trans fatty acids substitutes. International Journal of Food Science \& Technology, 42(5), 503-517. http://dx.doi.org/10.1111/j.1365-2621.2007.01571.x.
Wirkowska-Wojdyła, M., Bryś, J., Górska, A., \& Ostrowska-Ligęza, E. (2016). Effect of enzymatic interesterification on physiochemical and thermal properties of fat used in cookies. Lebensmittel-Wissenschaft + Technologie, 74, 99-105. http://dx.doi.org/10.1016/j.lwt.2016.07.040.

Xu, Z., Liu, P., Xu, G., He, Z., Ji, H., \& Wang, Q. (2017). Behenic acid pyrolysis to produce diesel-like hydrocarbons. Energy Conversion and Management, 138, 393-399. http://dx.doi.org/10.1016/j. enconman.2017.02.015

Zhao, S. Q., Hu, J. N., Zhu, X. M., Bai, C. Q., Peng, H. L., Xiong, H., Hu, J. W., \& Zhao, Q. (2014). Characteristics and feasibility of trans- free plastic fats through lipozyme TL IM-catalyzed interesterification of palm stearin and akebia trifoliata variety Australis seed oil. Journal of Agricultural and Food Chemistry, 62(14), 3293-3300. http://dx.doi. org/10.1021/jf500267e. PMid:24655125. 